\title{
Colorectal carcinogenesis: MSI-H versus MSI-L
}

\author{
Timothy M. Pawlik, Chandrajit P. Raut and Miguel A. Rodriguez-Bigas* \\ Department of Surgical Oncology, The University of Texas M.D. Anderson Cancer Center, Houston, Texas, USA
}

\begin{abstract}
Microsatellite instability (MSI) is a well-recognized phenomenon that is classically a feature of tumors in the hereditary non-polyposis colorectal syndrome. Ten to $15 \%$ of sporadic colorectal cancers, however, will have MSI. Microsatellite unstable tumors can be divided into two distinct MSI phenotypes: MSI-high (MSI-H) and MSI-low (MSI-L). MSI sporadic colorectal cancers with a high level of MSI (MSI-H) form a well defined group with distinct clinicopathologic features characterized by an overall better long-term prognosis. These sporadic MSI-H colorectal tumors most often arise from the epigenetic silencing of the mismatch repair gene MLH1. In contrast, MSI-L colorectal tumors have not been shown to differ in their clinicopathologic features or in most molecular features from microsatellite stable (MSS) tumors. Unlike MSI-H tumors, MSI-L tumors appear to arise through the chromosomal instability carcinogenesis pathway, similar to MSS tumors. Some groups have reported more frequent mutations in K-ras and in the methylation of methylguanine transferase in MSI-L tumors, but others have questioned these findings. Therefore, although the use of the MSI-L category is widespread, there continues to be some debate as to whether a discrete MSI-L group truly exists. Rather, it has been suggested that MSI-L tumors differ quantitatively from MSS tumors but do not differ qualitatively. Future studies will need to evaluate the specific mutations in non-MSI-H tumors in an attempt to sub-classify MSI-L tumors with regard to MSS tumors so that subtle differences between these two sub-groups can be identified.
\end{abstract}

\section{Introduction}

Colorectal cancer is both the third most common type of cancer, as well as the third leading cause of cancer-related deaths in North America [1]. In 2003, an estimated 145,000 new cases of colorectal cancer will be diagnosed with an associated 58,000 colorectal deaths [1]. The malignant transformation associated with colorectal carcinogenesis involves the stepwise accumulation of multiple genetic alterations that allow the growth of neoplastic cells [2-4]. Currently, adenocarinomas of the colon and rectum are believed to arise from two distinct molecular genetic pathways: one involving chromosomal instability (CIN) and the other involving microsatellite instability (MSI) [5-8]. CIN results from a series of genetic changes that involve

*Correspondence and Reprint Request: Miguel A. RodriguezBigas, MD, Department of Surgical Oncology, The University of Texas M.D. Anderson Cancer Center, 1515 Holcombe Boulevard, Box 444, Houston, Texas 77030, USA. Tel.: +1 713745 4955; Fax: +1 713745 5680; E-mail: mrodbig@mdanderson.org. the activation of proto-oncogenes such as K-ras, and inactivation of tumor-suppressor genes, such as APC, TP53, DCC, SMAD2, SMAD4 [2,9-12]. CIN tumors are characterized by a high frequency of allelic imbalance (most commonly involving chromosomal arms $5 \mathrm{q}, 8 \mathrm{p}, 17 \mathrm{p}$, and $18 \mathrm{q})$, chromosomal amplifications, and translocations [2]. Seventy-five to $80 \%$ of sporadic cases of colorectal carcinoma arise through the CIN pathway $[9,10]$.

The second pathway of colorectal carcinogenesis is the MSI pathway. In the MSI mutational pathway, colorectal cancers display increased rates of intragenic mutations of short, tandemly repeated DNA sequences known as microsatellites [13-15]. The phenomenon of MSI results from inactivation, mutational and/or epigenetic silencing of mismatch repair (MMR) genes. The primary function of the postreplicative MMR is to eliminate base-base mismatches and insertion/deletion loops that arise as a consequence of DNA polymerase slippage during DNA synthesis [10, 16,17]. Mutation rates in tumor cells with MMR deficiency are 100- to 1,000-fold more common as com- 
pared to normal cells $[18,19]$. The vast majority of hereditary non-polyposis colorectal cancer (HNPCC) patients will have microsatellite high (MSI-H) tumors. HNPCC is an autosomal-dominant condition that accounts for approximately $2-3 \%$ of all colorectal carcinomas. In most cases, the genetic basis for instability in MSI tumors is an inherited germline alteration in any one of the five human MMR genes: MSH2, MLH1, MSH6, PMS2, and PMS1 [20-23]. More specifically, germline mutations in MSH2 and MLH1 are responsible for most HNPCC families, while MSH6 is less common and PMS2 and PMS1 are rare [20,22].

MSI-H is also seen in $10-15 \%$ of sporadic nonHNPCC colorectal cancers. In patients with MSI$\mathrm{H}$ sporadic colorectal cancer, the basis for instability is usually an acquired hypermethylation of the MLH1 promoter with subsequent transcriptional silencing [24-28]. MSI-H sporadic colorectal cancers do not exhibit gross cytogenetic abnormalities, infrequently display allelic losses at tumor suppressor loci, and are usually not aneuploid [13,29-31]. Instead, MSI-H sporadic colorectal tumors accumulate mutations at microsatellite sequences in coding regions of specific genes that are implicated in tumor progression, such as TGF $\beta$ RII, IGFIIR, MSH3, MSH6, and BAX [32-35].

\section{Microsatellite Instability: High versus low}

Criteria and guidelines used to define MSI have evolved and, to some degree, remain somewhat elusive. MSI was initially described in independent publications from three groups in 1993, each who used unique descriptors for their findings $[13,15,36]$. Since that time, there has been a concerted effort to develop international criteria for the determination of MSI in colorectal cancer [37]. Despite this, the number, type, and identity of the microsatellites which should be used for MSI assessment remain unclear and the criteria for scoring MSI continue to vary among studies [38]. There is, however, a consensus that some markers, including mononucleotide repeats such as BAT25, BAT26, and BAT40 and the dinucleotide repeats D5S346, D2S123, and D17S250, are particularly useful for the identification of MSI tumors [39-42].

More recently, several studies have shown that colorectal cancers demonstrating the MSI phenomenon can be divided into two distinct MSI tumor phenotypes: MSI-high (MSH-H) and MSI-low (MSI-L). This division depends on the proportion of markers showing
MSI and on the type of microsatellite marker that is utilized. In the MSI-H group, the majority of tested markers exhibit instability, whereas in the MSI-L group only a minority of markers show evidence of MSI. The distinction between these two groups is highly dependent on both the type and the number of microsatellites analyzed. For example, dinucleotide markers demonstrate both MSI-H and MSI-L, whereas mononucleotide markers such as BAT26 and BAT40 are relatively specific for MSI-H cancers $[42,43]$. Based on this, some groups have distinguished between the type of tandem repeat as a reliable means of defining MSI$\mathrm{L}$, or have used specific markers, such as the complex repeat MYCL, which is believed to be more specific for MSI-L tumors [42,44,45]. With regard to the number of markers demonstrating instability, most groups have defined MSI-H as those tumors with more than about $30-40 \%$ of markers unstable and MSI-L as a level of instability lower than this threshold $[37,38,42,46]$.

Compared to MSI-L or microsatellite stable (MSS) tumors, MSI-H tumors have a distinct clinicopathologic phenotype [47-49]. MSI-H tumors tend to be poorly differentiated, right-sided, mucinous, have an expansile growth pattern, histologic heterogeneity, and increased tumor infiltrating lymphocytes with a prominent inflammatory reaction [5,50-53]. In addition, the carcinogenic pathway underlying MSI-H tumors (MMR repair defect) is believed to be distinct from the CIN pathway underlying non-MIS-H cancer. Based on these phenotypic as well as genetic differences, the distinction between MSI-H and non-MSI-H tumors has come to be universally accepted. In contrast, the MSI-L phenotype is not associated with distinct clinicopathological features or altered MLH1 or MSH2 expression and the biological basis of the MSI-L phenotype remains uncertain [28,37,42,44,54]. Given this, considerable controversy and debate remains around the validity and clinical utility of separating MSI-L tumors from MSS tumors.

\section{MSI-L: A distinct sub-group of sporadic colorectal carcinoma}

Some authors have argued that although MSI-L cancers may overlap more with MSS than MSI-H tumors, MSI-L still represents a distinct intermediate subset of colorectal cancers $[43,55]$. Although the MSI-L subset may not show distinct clinical, morphological, or molecular differences from the remaining MSS cancers (at least not to the degree seen between MSI-H and 
non-MSI-H tumors), there are certain molecular features that are distributed in a nonrandom basis within the non-MSI-H subset of colorectal cancers [56]. In order to establish MSI-L as a distinct subset of nonMSI-H cancers, these molecular features would need to be identified in a group of tumors (i.e. MSI-L tumors) at a rate more than would be expected by chance. Jass and others have argued that when a panel of relatively sensitive markers is used, approximately $8 \%$ of sporadic colorectal cancers can indeed be designated as MSI-L [55,56]. Futhermore, some markers (D2S123, MYCL) are mutated at a much higher rate outside the MSI-H subset [57]. It is also evident that some colorectal cancers show more extensive MSI-L than would be expected by chance while others are "superstable" [58]. Therefore, nonrandomly distributed features among non-MSI-H cancers - including chromosomal alterations, DNA methylation, and the K-ras mutation - are hard to simply explain away by claiming that they are due to "more cell divisions" [55,59-62].

Kambara et al. examined the molecular events in early colorectal cancer with regard to MSI [60]. These investigators noted a significantly higher frequency of the low-level MSI (MSI-L) phenotype in early colorectal cancers $(51.0 \%)$ compared with advanced colorectal cancers $(25.9 \% ; p=0.0001)$ [60]. In early colorectal cancers, tumors with MSI-L phenotype were significantly different from MSS tumors with respect to loss of heterozygosity ( $\mathrm{LOH})$ at $1 \mathrm{p} 32(48.6 \%$ versus $18.9 \%)$ and 8 p12-22 (71.1\% versus $39.0 \%)$. In advanced colorectal cancers, the frequency of $\mathrm{LOH}$ at $1 \mathrm{p} 32,2 \mathrm{p} 16$, 7q31, 8p12-22, and 17q11 was significantly higher in MSI-L than that in MSS cancers. In addition, a high frequency of cancers with MSI-L phenotype was observed in early colorectal cancers $(51.0 \%)$ compared with advanced lesions (25.9\%) [60]. K-ras mutation was also more frequently observed in advanced MSIL colorectal cancers, whereas no such correlation was observed in early colorectal tumors with MSI-L [60]. Others have corroborated this finding of more frequent K-ras mutations in MSI-L as compared to MSS tumors [55,59]. In each of 3 independent studies, K-ras mutation was found to be significantly more frequent in MSI-L ( $41 \%$ to $50 \%$ ) versus MSS cancers (18\% to $30 \%)[55,59,60]$. The high frequency of K-ras mutation appears to occur in non-MSI-H cancers with the CpG island methylator phenotype (CIMP) and be associated with methylation of the DNA repair gene methylguanine transferase (MGMT) [61,63]. Whitehall et al. has reported that methylation of MGMT is associated with MSI-L colorectal cancers with instability at the D2S123 marker [44]. Loss of expression of the MGMT gene may represent the underlying molecular mechanism for MSI-L tumors [44]. Jass et al. has postulated that inactivation of MGMT may result in excessive production of methylG:T mismatches which would increase the probability of errors during DNA resynthesis that escape the mismatch repair system [56].

Based on the common features of MSI-L, K-ras mutation and serrated morphology, Jass and others have suggested that the family of serrated polyps (i.e. serrated adenomas, mixed polyps, and hyperplastic polyps) and MSI-L colorectal cancer might be related histogenetically [43,64]. Given that the adenomacarcinoma sequence in sporadic MSI-H colorectal cancer is found only rarely and that MSI in adenomas occurs mainly at a low level (MSI-L), Jass and co-workers have postulated an alternative colorectal tumorigenesis pathway termed the "serrated pathway" [64-67]. It has been observed that MSI-L status is frequent in serrated polyps showing dysplasia, but not within traditional adenomas [64]. Due to the presence of MSI-L in some hyperplastic polyps and the lack of sporadic MSI-H adenomas, Jass has suggested that many sporadic MSI-H cancers may arise along an accelerated "serrated" pathway: hyperplastic polyp to serrated adenoma to cancer. All serrated or hyperplastic polyps, however, do not appear to be at the same risk of malignant transformation. Rather, a heterogeneity in hyperplastic polyps may exist, whereby left sided and distal hyperplastic polyps may continue to be viewed as innocuous, while proximal lesions need to be considered at increased risk for colorectal carcinogenesis [43,68].

In the model proposed by Jass, proximal serrated polyps may progress to MSI-H colorectal cancer through the inactivation of HPP1 in a background of disordered methylation [43]. The precise role of HPP1 is unknown, but it appears to be involved in the regulation of $\operatorname{TGF} \beta$, which is known to be involved in regulating growth, differentiation and cell migration [69, 70]. Those hyperplastic polyps with the MSI-L phenotype are thereby "primed" for the subsequent loss of MLH1 expression and the high mutator pathway [43]. Methylation of the DNA mismatch repair gene MLH1 would result in the MSI-H phenotype with progression to malignancy occurring rapidly through the acquisition of DNA instability [43,68]. This, in part, could explain why a paucity of MSI-H adenomas are clinically encountered.

Recently, a high frequency of BRAF mutation has been documented in serrated polyps, including both serrated adenomas and hyperplastic polyps [71]. BRAF 
is one of three RAF genes that encodes a cytoplasmic serine/threonine kinase which is regulated by binding to RAS and can subsequently lead to malignant transformation. Mutation of BRAF is very infrequent in conventional adenomas. BRAF mutation, however, is known to be associated with MSI-H colorectal cancer and more recently this association has been narrowed done exclusively to the sporadic MSI-H subset [72, 73]. Since serrated polyps and sporadic MSI-H colorectal cancer are the principal colorectal lesions that have BRAF mutation, the link between the two seems certain. The high incidence of BRAF mutations in hyperplastic polyps and serrated adenomas is consistent with the notion that the majority of colorectal cancers carrying BRAF mutations have progressed through the serrated carcinoma pathway [71]. BRAF mutation is also found in the non-MSI-H subset of colorectal cancers with extensive DNA methylation, though not to the same extent as the sporadic MSI-H subset (personal correspondence). This suggests that serrated polyps may be the precursors of CIMP colorectal cancers that may be non-MSI-H as well as MSI-H.

BRAF is immediately downstream of K-ras, which is also associated with serrated polyps and CIMP colorectal cancers [74]. BRAF and K-ras mutations, however, are mutually exclusive [72]. It seems that mutation of one or the other of these closely related oncogenes is associated with CIMP status and can perhaps synergize with a gene (or genes) that are silenced by methylation. This may provide a mechanism for the early initiation of the serrated pathway. The fact that the pathway can bifurcate does not necessarily diminish its importance, but rather may increase its significance in terms of its potential overall contribution to tumorigenesis.

Recently, Whitehall et al. examined a small series of heavily methylated non-MSI-H colorectal cancers and showed that most of these colorectal cancers were MSI-L [75]. MSI-L status, however, does not appear to be restricted to the non-MSI-H CIMP-high subset of colorectal cancers. Rather, colorectal cancers with the MSI-L phenotype are more heterogeneous than the MSI-H group. In other words, some may be classified with the sporadic MSI-H subset (e.g. showing extensive methylation, either BRAF or K-ras mutation, and an origin in serrated polyps), whereas other will not. Being a small and heterogeneous subset, it will only be possible to characterize fully MSI-L colorectal cancers by applying a multilayered and meticulous approach to a very large series of cases.

One such novel approach comes from recent data derived from the use of the cDNA microarray, which supports the use of MSI-L as a natural sub-grouping of colorectal cancers [76]. To evaluate the impact of MSI status on global molecular phenotypes and to determine the importance of MSI relative to other molecular and clinical features, Mori et al. examined 41 colon cancers using cDNA microarray [76]. Interestingly, MSIL cancers were clearly distinguishable from non-MSIL tumors by principle component 10 (the "MSI-L separator"). Of note, several genes identified on the basis of high loading values in the MSI-L separator component have previously been implicated in the biology of MSI-L tumors. For example, the loading value of the DNA repair gene MGMT in component 10 was negative, consistent with decreased expression of MGMT in MSI-L tumors due to promoter hypermethylation [44, 76]. Another relevant gene was selenoprotein $P$, which has previously been postulated as a possible cause of disrupted DNA MMR in MSI-L tumors [77]. This data, therefore, appears to substantiate the distinction between MSS and MSI-L tumors based on molecular phenotypes. Of note, the impact of the MSI-L distinction was more subtle than that of the MSI-H on molecular phenotype, which corresponds to the known clinicopathologic similarities between MSS and MSI-L tumors [28,78].

\section{Continuing questions and controversies}

In spite of the reports noted above, there is still controversy over whether MSI-L tumors exist as a distinct sub-group of colorectal cancer. Some authors have argued that because microsatellite repeat slippage occurs about every 1,000 to 10,000 divisions in normal cells, the clonal nature of cancers would make this slippage detectable and therefore account for at least some MSIL tumors [58]. That is, given the use of enough makers, it may be that all colorectal cancers will exhibit some level of MSI [37]. In two independent studies examining sporadic colorectal carcinomas, $68 \%$ and $79 \%$ of the non-MSI-H tumors exhibited some MSI and therefore could nominally be classified as MSI-L [57,58]. In the study by Halford et al., however, no evidence for a discrete MSI-L group was identified. No association was found between MSI-L (or the level of MSI) and any clinicopathological or molecular variable, including K-ras mutation and LOH at APC [57]. A recent meta-analysis of those studies investigating the relation of K-ras mutation and MSI-L similarly failed to show a significantly higher frequency of K-ras in MSI-L cancers. Rather a significant heterogeneity was 
found in the frequency of K-ras mutations in MSI-L and MSS tumors, presumably some of which was due to the different methods used to assess MSI in each group [38]. Critics of the MSI-L sub-classification suggest that the greater variation in the non-MSI-H group may be more due to MSI-L cancers being quantitatively different from MSS tumors in some way (i.e. larger number of cell divisions, somatic mutational load, or germ-line genotype), rather than there actually being a true qualitative distinction from MSS cancers [38,58]. In this regard, Gonzalez-Garcia et al. specifically considered whether the frequency of MSI in the cancers they examined better fit a bimodal (MSI positive, MSS) or trimodal (MSI-H, MSI-L, and MSS) distribution and found no evidence for a separate category for MSI-L cancers [38,79].

Finally, some authors have questioned the validity of the "serrated adenoma pathway" and the role of MSI-L in sporadic colorectal carcinogenesis. Although a "serrated pathway" of colorectal carcinogenesis may exist, critics of MSI-L's role in tumorigenesis suggest that an alternative explanation for the reason that MSI-L is found very rarely in sporadic, non-serrated adenomas is that MSI-H do develop from classical adenomas, but that MSI is not acquired until after malignant progression [38]. In support of this, Sawyer et al. analyzed 39 serrated adenomas from 27 patients to define the molecular characteristics of serrated adenomas of the colorectum [80]. MSI was found in $<5 \%$ of cases and there was no loss of expression of MMR proteins. Instead, a variety of genetic defects including APC mutation/LOH, $\beta$-catenin mutation and CRAC1 LOH were found in a number of serrated adenomas. Given these findings, the authors concluded that no "serrated pathway" per se existed, but rather the pathway of colorectal tumorigenesis for serrated adenomas appeared to be heterogeneous and could not be accounted for by changes in known genes [80].

\section{MSI status and prognostic implications}

It is clear that MSI status has prognostic implications. Retrospective and population-based studies have been published confirming an improved survival in patients with MSI-H versus non-MSI-H colorectal tumors. In the Ontario population-based study, a series of 607 patients were diagnosed with colorectal cancer at age 50 or younger. Multivariate analysis revealed that MSI-H was an independent prognostic factor, along with stage at diagnosis, histology of tumor, and tumor grade [46].
Furthermore, regardless of the depth of tumor invasion, colorectal cancers with high-frequency MSI had a decreased likelihood of metastasizing to regional lymph nodes or distant organs [46]. Based on the findings of this study, high-frequency MSI in colorectal cancer appears to be independently predictive of a relatively favorable outcome [46]. Similarly, in the Utah and Northern California population-based study of 1,026 patients, there was a relationship between MSI-H and improved prognosis independent of stage, site, tumor grade, and age [81]. In fact, the authors reported that there was a $60 \%$ decrease in colorectal-related deaths in patients with MSI-H tumors. Most of the risk reduction occurred in Stage III patients whose tumors behaved as Stage II if the tumor was MSI-H [81]. A retrospective analysis of 460 patients with Stage III colorectal cancer, enrolled in five national trials of adjuvant 5 -fluorouracil (FU)-based chemotherapy, revealed that patients with MSI tumors and mutations in the type II receptor for TGF- $\beta 1$ had a better prognosis [82]. It therefore appears that not all MSI-H tumors behave the same. In one study, mutation of the gene for the type II receptor for TGF- $\beta 1$ in cancers with high levels of microsatellite instability had a more favorable outcome [81,82].

Even though the majority of the published data suggest that colorectal cancer patients with MSI-H tumors have an improved prognosis, there are still some conflicting reports. Investigators from Scotland recently reported that patients less than 30 years of age at diagnosis who had MSI-H colorectal cancer had a worse chance of survival than those patients whose tumors were MSS [83]. Younger patients had excess MSI tumors, mucinous tumors, and more advanced disease [83]. The relative risk of death associated with tumor MSI was 0.87 in the cohort of patients $<30$ years of age as compared to 0.11 for the control cohort of older patients [83].

MSI status also appears to play a critical role in the responsiveness of colorectal tumors to certain types of chemotherapy [84]. Recently a study by Ribic et al. showed that fluorouracil-based adjuvant chemotherapy benefited patients with stage II or stage III colon cancer with MSS or MSI-L, but not those with tumors exhibiting MSI-H [84]. In the absence of adjuvant chemotherapy, the patients with tumors displaying high-frequency microsatellite instability had significantly longer overall survival than patients with tumors exhibiting microsatellite stability or low-frequency microsatellite instability. When the analysis was limited to the group receiving adjuvant chemotherapy, however, patients with MSI-H tumors did not have a significant increase in 
overall survival as compared with patients with MSS or MSI-L tumors [84]. Therefore, it appeared that, opposed to the patients with non-MSI-H tumors, the MSI$\mathrm{H}$ group did not benefit from the adjuvant chemotherapy.

Although there is a preponderance of data indicating a significant difference in the prognosis of MSI-H versus non-MSI-H tumors, currently there is no data to support a distinction between MSI-L and MSS cancers with regards to prognosis. Rather, tumors with lowfrequency microsatellite instability have been found to have similar clinical and prognostic features to MSS tumors $[46,53,79,84]$. In multiple studies, a bimodal distribution of MSI (MSI-H versus non-MSI-H), rather than a trimodal distribution (MSI-H versus MSI-L versus MSS) has been shown to more accurately reflect the prognosis and natural history of colorectal tumors [46, $79,84]$.

\section{Conclusion}

MSI is a well-recognized and accepted phenomenon. The existence of MSI-H tumors as a unique subclassification of colorectal tumors has been unequivocally established both phenotypically and genetically. What remains to be determined is whether an intermediate classification of MSI-L tumors exists between those tumors classified as MSS and MSI-H. To date, the MSI-L subset has not shown any distinct clinical or morphological differences from the remaining MSS cancers. Given this, some may wonder why any debate around the existence of MSI-L status is even clinically relevant or warranted. MSI-L status is important insofar as MSI-L might serve as the by-product of a DNA repair defect. Identifying this defect, however subtle it may be, could hold potential importance as it may define a subgroup of tumors associated with a distinct natural history and an altered response to chemotherapeutic agents. Because of this, the possibility that a "mild mutator" pathway may be driven by a DNA repair defect in MSI-L tumors warrants additional scientific and clinical research. It is imperative that future prospective studies not only evaluate the role of MSI as a prognostic factor, but that these studies also examine specific mutations in an attempt to sub-classify MSI-L with regard to MSS tumors so that subtle differences in prognosis and natural history between these two sub-groups can be identified.

\section{References}

[1] A. Jemal, T. Murray, A. Samuels, A. Ghafoor, E. Ward and M.J. Thun, Cancer statistics, CA Cancer J Clin 53 (2003), 5-26.

[2] E.R. Fearon, Molecular genetics of colorectal cancer, Ann $N$ Y Acad Sci 768 (1995), 101-110.

[3] K.W. Kinzler and B. Vogelstein, Lessons from hereditary colorectal cancer, Cell 87 (1996), 159-170.

[4] P.C. Nowell, The clonal evolution of tumor cell populations, Science 194 (1976), 23-28.

[5] J.R. Jass, Pathology of hereditary nonpolyposis colorectal cancer, Ann N Y Acad Sci 910 (2000), 62-73; discussion -4.

[6] B. Dutrillaux, Pathways of chromosome alteration in human epithelial cancers, Adv Cancer Res 67 (1995), 59-82.

[7] C. Lengauer, K.W. Kinzler and B. Vogelstein, Genetic instability in colorectal cancers, Nature 386 (1997), 623-627.

[8] M.A. Sweezy and R. Fishel, Multiple pathways leading to genomic instability and tumorigenesis, Ann N Y Acad Sci $\mathbf{7 2 6}$ (1994), 165-177.

[9] B. Vogelstein, E.R. Fearon, S.R. Hamilton, S.E. Kern, A.C. Preisinger and M. Leppert et al., Genetic alterations during colorectal-tumor development, NEngl J Med 319 (1988), 525532.

[10] E.R. Fearon and B. Vogelstein, A genetic model for colorectal tumorigenesis, Cell 61 (1990), 759-767.

[11] E.R. Fearon and W.E. Pierceall, The deleted in colorectal cancer (DCC) gene: a candidate tumour suppressor gene encoding a cell surface protein with similarity to neural cell adhesion molecules, Cancer Surv 24 (1995), 3-17.

[12] D.P. Cahill, C. Lengauer, J. Yu, G.J. Riggins, J.K. Willson and S.D. Markowitz et al., Mutations of mitotic checkpoint genes in human cancers, Nature 392 (1998), 300-303.

[13] S.N. Thibodeau, G. Bren and D. Schaid, Microsatellite instability in cancer of the proximal colon, Science 260 (1993), 816-819.

[14] Y. Ionov, M.A. Peinado, S. Malkhosyan, D. Shibata and M. Perucho, Ubiquitous somatic mutations in simple repeated sequences reveal a new mechanism for colonic carcinogenesis, Nature 363 (1993), 558-561.

[15] L.A. Aaltonen, P. Peltomaki, F.S. Leach, P. Sistonen, L. Pylkkanen and J.P. Mecklin et al., Clues to the pathogenesis of familial colorectal cancer, Science 260 (1993), 812-816.

[16] R.D. Kolodner and G.T. Marsischky, Eukaryotic DNA mismatch repair, Curr Opin Genet Dev 9 (1999), 89-96.

[17] J. Jiricny and M. Nystrom-Lahti, Mismatch repair defects in cancer, Curr Opin Genet Dev 10 (2000), 157-161.

[18] N.P. Bhattacharyya, A. Skandalis, A. Ganesh, J. Groden and M. Meuth, Mutator phenotypes in human colorectal carcinoma cell lines, Proc Natl Acad Sci USA 91 (1994), 6319-6323.

[19] J.R. Eshleman, E.Z. Lang, G.K. Bowerfind, R. Parsons, B. Vogelstein and J.K. Willson et al., Increased mutation rate at the hprt locus accompanies microsatellite instability in colon cancer, Oncogene 10 (1995), 33-37.

[20] P. Peltomaki and A. de la Chapelle, Mutations predisposing to hereditary nonpolyposis colorectal cancer, Adv Cancer Res 71 (1997), 93-119.

[21] M. Aarnio, R. Sankila, E. Pukkala, R. Salovaara, L.A. Aaltonen and A. de la Chapelle et al., Cancer risk in mutation carriers of DNA-mismatch-repair genes, Int J Cancer 81 (1999), 214-218.

[22] P. Peltomaki and H.F. Vasen, Mutations predisposing to hereditary nonpolyposis colorectal cancer: database and results of a collaborative study. The International Collaborative Group on 
Hereditary Nonpolyposis Colorectal Cancer, Gastroenterology 113 (1997), 1146-1158.

[23] P. Peltomaki, DNA mismatch repair and cancer, Mutat Res 488 (2001), 77-85.

[24] M.L. Veigl, L. Kasturi, J. Olechnowicz, A.H. Ma, J.D. Lutterbaugh and S. Periyasamy et al., Biallelic inactivation of hMLH1 by epigenetic gene silencing, a novel mechanism causing human MSI cancers, Proc Natl Acad Sci USA 95 (1998), 8698-8702.

[25] J.M. Cunningham, E.R. Christensen, D.J. Tester, C.Y. Kim, P.C. Roche and L.J. Burgart et al., Hypermethylation of the hMLH1 promoter in colon cancer with microsatellite instability, Cancer Res 58 (1998), 3455-3460.

[26] M.F. Kane, M. Loda, G.M. Gaida, J. Lipman, R. Mishra and H. Goldman et al., Methylation of the hMLH1 promoter correlates with lack of expression of hMLH1 in sporadic colon tumors and mismatch repair-defective human tumor cell lines, Cancer Res 57 (1997), 808-811.

[27] J.G. Herman, A. Umar, K. Polyak, J.R. Graff, N. Ahuja and J.P. Issa et al., Incidence and functional consequences of hMLH1 promoter hypermethylation in colorectal carcinoma, Proc Natl Acad Sci USA 95 (1998), 6870-6875.

[28] S.N. Thibodeau, A.J. French, J.M. Cunningham, D. Tester, L.J. Burgart and P.C. Roche et al., Microsatellite instability in colorectal cancer: different mutator phenotypes and the principal involvement of hMLH1, Cancer Res 58 (1998), 17131718.

[29] S. Olschwang, R. Hamelin, P. Laurent-Puig, B. Thuille, Y. De Rycke and Y.J. Li et al., Alternative genetic pathways in colorectal carcinogenesis, Proc Natl Acad Sci USA 94 (1997), 12122-12127.

[30] R.A. Lothe, P. Peltomaki, G.I. Meling, L.A. Aaltonen, M. Nystrom-Lahti and L. Pylkkanen et al., Genomic instability in colorectal cancer: relationship to clinicopathological variables and family history, Cancer Res $\mathbf{5 3}$ (1993), 5849-5852.

[31] J.R. Eshleman, G. Casey, M.E. Kochera, W.D. Sedwick, S.E. Swinler and M.L. Veigl et al., Chromosome number and structure both are markedly stable in RER colorectal cancers and are not destabilized by mutation of p53, Oncogene 17 (1998), 719-725.

[32] R.F. Souza, R. Appel, J. Yin, S. Wang, K.N. Smolinski and J.M. Abraham et al. Microsatellite instability in the insulinlike growth factor II receptor gene in gastrointestinal tumours, Nat Genet 14 (1996), 255-257.

[33] R. Parsons, L.L. Myeroff, B. Liu, J.K. Willson, S.D. Markowitz and K.W. Kinzler et al., Microsatellite instability and mutations of the transforming growth factor beta type II receptor gene in colorectal cancer, Cancer Res 55 (1995), $5548-5550$.

[34] S. Malkhosyan, N. Rampino, H. Yamamoto and M. Perucho, Frameshift mutator mutations, Nature 382 (1996), 499-500.

[35] N. Rampino, H. Yamamoto, Y. Ionov, Y. Li, H. Sawai and J.C. Reed et al., Somatic frameshift mutations in the BAX gene in colon cancers of the microsatellite mutator phenotype, Science 275 (1997), 967-969.

[36] P. Peltomaki, L.A. Aaltonen, P. Sistonen, L. Pylkkanen, J.P. Mecklin and H. Jarvinen et al., Genetic mapping of a locus predisposing to human colorectal cancer, Science 260 (1993), 810-812.

[37] C.R. Boland, S.N. Thibodeau, S.R. Hamilton, D. Sidransky, J.R. Eshleman and R.W. Burt et al., A National Cancer Institute Workshop on Microsatellite Instability for cancer detection and familial predisposition: development of international criteria for the determination of microsatellite instability in colorectal cancer, Cancer Res 58 (1998), 5248-5257.

[38] I. Tomlinson, S. Halford, L. Aaltonen, N. Hawkins and R. Ward, Does MSI-low exist? J Pathol 197 (2002), 6-13.

[39] J.M. Hoang, P.H. Cottu, B. Thuille, R.J. Salmon, G. Thomas and R. Hamelin, BAT-26, an indicator of the replication error phenotype in colorectal cancers and cell lines, Cancer Res $\mathbf{5 7}$ (1997), 300-303.

[40] X.P. Zhou, J.M. Hoang, P. Cottu, G. Thomas and R. Hamelin, Allelic profiles of mononucleotide repeat microsatellites in control individuals and in colorectal tumors with and without replication errors, Oncogene 15 (1997), 1713-1718.

[41] J.G. Stone, I.P. Tomlinson and R.S. Houlston, Optimising methods for determining RER status in colorectal cancers, Cancer Lett 149 (2000), 15-20.

[42] W. Dietmaier, S. Wallinger, T. Bocker, F. Kullmann, R. Fishel and J. Ruschoff, Diagnostic microsatellite instability: definition and correlation with mismatch repair protein expression, Cancer Res 57 (1997), 4749-4756.

[43] J.R. Jass, J. Young and B.A. Leggett, Hyperplastic polyps and DNA microsatellite unstable cancers of the colorectum, Histopathology 37 (2000), 295-301.

[44] V.L. Whitehall, M.D. Walsh, J. Young, B.A. Leggett and J.R. Jass, Methylation of O-6-methylguanine DNA methyltransferase characterizes a subset of colorectal cancer with lowlevel DNA microsatellite instability, Cancer Res 61 (2001), $827-830$

[45] J. Young, J. Searle, R. Buttenshaw, L. Thomas, M. Ward and G. Chenevix-Trench et al., An Alu VpA marker on chromosome I demonstrates that replication errors manifest at the adenoma-carcinoma transition in sporadic colorectal tumors, Genes Chromosomes Cancer 12 (1995), 251-254.

[46] R. Gryfe, H. Kim, E.T. Hsieh, M.D. Aronson, E.J. Holowaty and S.B. Bull et al. Tumor microsatellite instability and clinical outcome in young patients with colorectal cancer, $N$ Engl $J$ Med 342 (2000), 69-77.

[47] J.K. Greenson, J.D. Bonner, O. Ben-Yzhak, H.I. Cohen, I. Miselevich and M.B. Resnick et al., Phenotype of microsatellite unstable colorectal carcinomas: Well-differentiated and focally mucinous tumors and the absence of dirty necrosis correlate with microsatellite instability, Am J Surg Pathol $\mathbf{2 7}$ (2003), 563-570.

[48] J.R. Jass, Towards a molecular classification of colorectal cancer, Int J Colorectal Dis 14 (1999), 194-200.

[49] H. Kim, J. Jen, B. Vogelstein and S.R. Hamilton, Clinical and pathological characteristics of sporadic colorectal carcinomas with DNA replication errors in microsatellite sequences, $\mathrm{Am}$ J Pathol 145 (1994), 148-156.

[50] H.T. Lynch, T. Smyrk and J.F. Lynch, Overview of natural history, pathology, molecular genetics and management of HNPCC (Lynch Syndrome), Int J Cancer 69 (1996), 38-43.

[51] J. Alexander, T. Watanabe, T.T. Wu, A. Rashid, S. Li and S.R. Hamilton, Histopathological identification of colon cancer with microsatellite instability, Am J Pathol 158 (2001), 527-535.

[52] J.R. Jass, K.A. Do, L.A. Simms, H. Iino, C. Wynter and S.P. Pillay et al., Morphology of sporadic colorectal cancer with DNA replication errors, Gut 42 (1998), 673-679.

[53] R. Ward, A. Meagher, I. Tomlinson, T. O'Connor, M. Norrie and R. Wu et al., Microsatellite instability and the clinicopathological features of sporadic colorectal cancer, Gut $\mathbf{4 8}$ (2001), 821-829.

[54] Y.R. Parc, K.C. Halling, L. Wang, E.R. Christensen, J.M. Cunningham and A.J. French et al., HMSH6 alterations in 
patients with microsatellite instability-low colorectal cancer, Cancer Res 60 (2000), 2225-2231.

[55] J.R. Jass, K.G. Biden, M.C. Cummings, L.A. Simms, M. Walsh and E. Schoch et al., Characterisation of a subtype of colorectal cancer combining features of the suppressor and mild mutator pathways, J Clin Pathol 52 (1999), 455-460.

[56] J.R. Jass, V.L. Whitehall, J. Young, B. Leggett, S.J. Meltzer and N. Matsubara et al., Correspondence re: P. Laiho et al., Low-level microsatellite instability in most colorectal carcinomas, Cancer Res 62 (2002), 1166-1170, Cancer Res 62 (2002), 5988-5989; author reply 9-90.

[57] P. Laiho, V. Launonen, P. Lahermo, M. Esteller, M. Guo and J.G. Herman et al., Low-level microsatellite instability in most colorectal carcinomas, Cancer Res 62 (2002), 1166-1170.

[58] S. Halford, P. Sasieni, A. Rowan, H. Wasan, W. Bodmer and I. Talbot et al., Low-level microsatellite instability occurs in most colorectal cancers and is a nonrandomly distributed quantitative trait, Cancer Res 62 (2002), 53-57.

[59] M. Konishi, R. Kikuchi-Yanoshita, K. Tanaka, M. Muraoka, A. Onda and Y. Okumura et al., Molecular nature of colon tumors in hereditary nonpolyposis colon cancer, familial polyposis, and sporadic colon cancer, Gastroenterology 111 (1996), 307317.

[60] T. Kambara, N. Matsubara, H. Nakagawa, K. Notohara, T Nagasaka and T. Yoshino et al., High frequency of low-level microsatellite instability in early colorectal cancer, Cancer Res 61 (2001), 7743-7746

[61] M. Toyota, M. Ohe-Toyota, N. Ahuja and J.P. Issa, Distinct genetic profiles in colorectal tumors with or without the $\mathrm{CpG}$ island methylator phenotype, Proc Natl Acad Sci USA 97 (2000), 710-715.

[62] P.H. Rooney, A. Boonsong, J.A. McKay, S. Marsh, D.A. Stevenson and G.I. Murray et al., Colorectal cancer genomics: evidence for multiple genotypes which influence survival, $\mathrm{Br}$ $J$ Cancer 85 (2001), 1492-1498.

[63] M. Esteller, M. Toyota, M. Sanchez-Cespedes, G. Capella, M.A. Peinado and D.N. Watkins et al., Inactivation of the DNA repair gene O6-methylguanine-DNA methyltransferase by promoter hypermethylation is associated with $\mathrm{G}$ to $\mathrm{A} \mathrm{mu-}$ tations in K-ras in colorectal tumorigenesis, Cancer Res 60 (2000), 2368-2371.

[64] H. Iino, J.R. Jass, L.A. Simms, J. Young, B. Leggett and Y. Ajioka et al., DNA microsatellite instability in hyperplastic polyps, serrated adenomas, and mixed polyps: a mild mutator pathway for colorectal cancer? J Clin Pathol 52 (1999), 5-9.

[65] J.R. Jass, Serrated adenoma and colorectal cancer, J Pathol 187 (1999), 499-502.

[66] J.R. Jass, Serrated route to colorectal cancer: back street or super highway? J Pathol 193 (2001), 283-285.

[67] J. Young, K.G. Biden, L.A. Simms, P. Huggard, R. Karamatic and H.J. Eyre et al., HPP1: a transmembrane protein-encoding gene commonly methylated in colorectal polyps and cancers, Proc Natl Acad Sci USA 98 (2001), 265-270.

[68] N.J. Hawkins and R.L. Ward, Sporadic colorectal cancers with microsatellite instability and their possible origin in hyperplastic polyps and serrated adenomas, J Natl Cancer Inst $\mathbf{9 3}$ (2001), 1307-1313.

[69] T. Uchida, K. Wada, T. Akamatsu, M. Yonezawa, H. Noguchi and A. Mizoguchi et al., A novel epidermal growth factorlike molecule containing two follistatin modules stimulates tyrosine phosphorylation of erbB-4 in MKN28 gastric cancer cells, Biochem Biophys Res Commun 266 (1999), 593-602.

[70] K.G. Biden and J.P. Young, L.A. S. HPP1: a novel transmembrane protein commonly methylated in colorectal polyps and cancers, 91st Proceedings of the Am Assoc Cancer Research 41 (2000), LB37.

[71] T.L. Chan, W. Zhao, S.Y. Leung and S.T. Yuen, BRAF and KRAS mutations in colorectal hyperplastic polyps and serrated adenomas, Cancer Res 63 (2003), 4878-4881.

[72] H. Rajagopalan, A. Bardelli, C. Lengauer, K.W. Kinzler, B. Vogelstein and V.E. Velculescu, Tumorigenesis: RAF/RAS oncogenes and mismatch-repair status, Nature 418 (2002), 934.

[73] L. Wang, J.M. Cunningham, J.L. Winters, J.C. Guenther, A.J. French and L.A. Boardman et al., BRAF mutations in colon cancer are not likely attributable to defective DNA mismatch repair, Cancer Res 63 (2003), 5209-5212.

[74] M. Toyota, N. Ahuja, M. Ohe-Toyota, J.G. Herman, S.B. Baylin and J.P. Issa, CpG island methylator phenotype in colorectal cancer, Proc Natl Acad Sci USA 96 (1999), 8681-8686.

[75] V.L. Whitehall, C.V. Wynter, M.D. Walsh, L.A. Simms, D. Purdie and N. Pandeya et al., Morphological and molecular heterogeneity within nonmicrosatellite instability-high colorectal cancer, Cancer Res 62 (2002), 6011-6014.

[76] Y. Mori, F.M. Selaru, F. Sato, J. Yin, L.A. Simms and Y. Xu et al., The impact of microsatellite instability on the molecular phenotype of colorectal tumors, Cancer Res 63 (2003), 45774582 .

[77] C.L. Chang, G. Marra, D.P. Chauhan, H.T. Ha, D.K. Chang and L. Ricciardiello et al., Oxidative stress inactivates the human DNA mismatch repair system, Am J Physiol Cell Physiol $\mathbf{2 8 3}$ (2002), C148-C154.

[78] R. Gafa, I. Maestri, M. Matteuzzi, A. Santini, S. Ferretti and L. Cavazzini et al., Sporadic colorectal adenocarcinomas with high-frequency microsatellite instability, Cancer 89 (2000), 2025-2037.

[79] I. Gonzalez-Garcia, V. Moreno, M. Navarro, J. Marti-Rague, E. Marcuello and C. Benasco et al., Standardized approach for microsatellite instability detection in colorectal carcinomas, $J$ Natl Cancer Inst 92 (2000), 544-549.

[80] E.J. Sawyer, A. Cerar, A.M. Hanby, P. Gorman, M. Arends and I.C. Talbot et al., Molecular characteristics of serrated adenomas of the colorectum, Gut $\mathbf{5 1}$ (2002), 200-206.

[81] W.S. Samowitz, K. Curtin, K.N. Ma, D. Schaffer, L.W. Coleman and M. Leppert et al., Microsatellite instability in sporadic colon cancer is associated with an improved prognosis at the population level, Cancer Epidemiol Biomarkers Prev $\mathbf{1 0}$ (2001), 917-923.

[82] T. Watanabe, T.T. Wu, P.J. Catalano, T. Ueki, R. Satriano and D.G. Haller et al., Molecular predictors of survival after adjuvant chemotherapy for colon cancer, $N$ Engl J Med 344 (2001), 1196-1206.

[83] S.M. Farrington, A.J. McKinley, A.D. Carothers, C. Cunningham, V.J. Bubb and L. Sharp et al., Evidence for an age-related influence of microsatellite instability on colorectal cancer survival, Int J Cancer 98 (2002), 844-850.

[84] C.M. Ribic, D.J. Sargent, M.J. Moore, S.N. Thibodeau, A.J. French and R.M. Goldberg et al., Tumor microsatelliteinstability status as a predictor of benefit from fluorouracilbased adjuvant chemotherapy for colon cancer, $N$ Engl J Med 349 (2003), 247-257. 


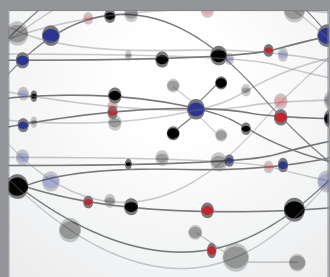

The Scientific World Journal
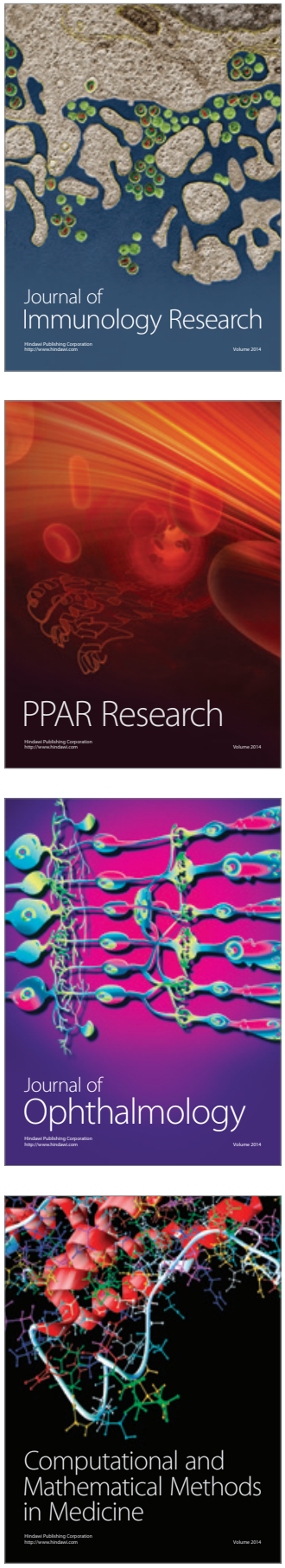

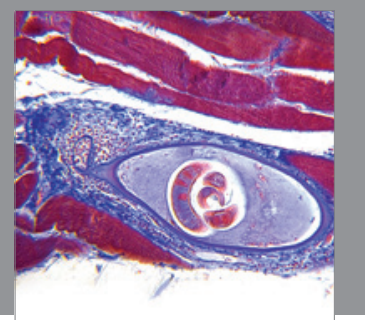

Gastroenterology

Research and Practice
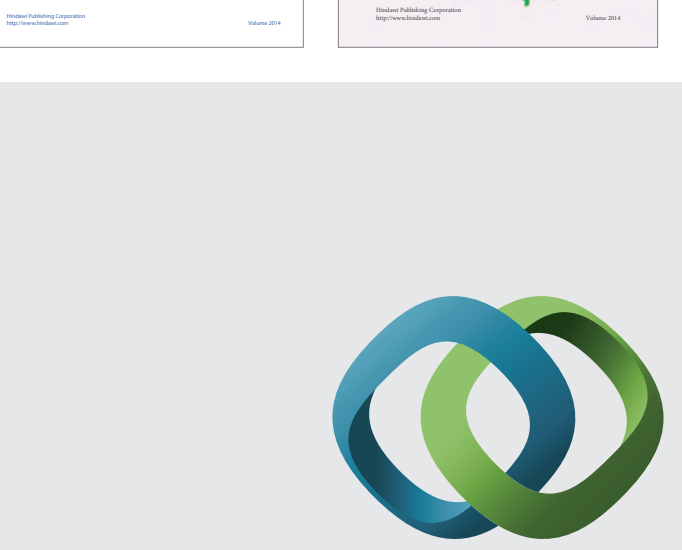

\section{Hindawi}

Submit your manuscripts at

http://www.hindawi.com
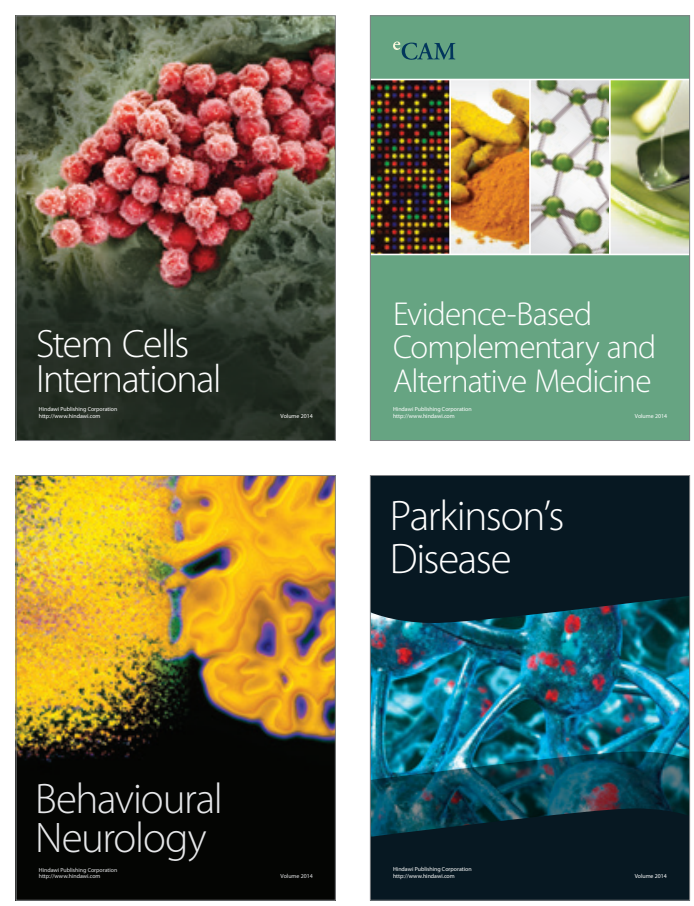

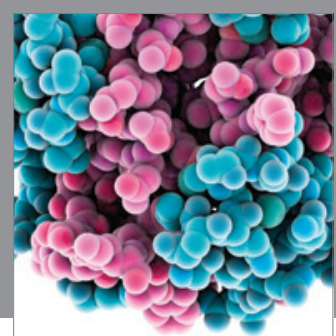

Journal of
Diabetes Research

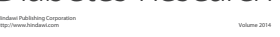

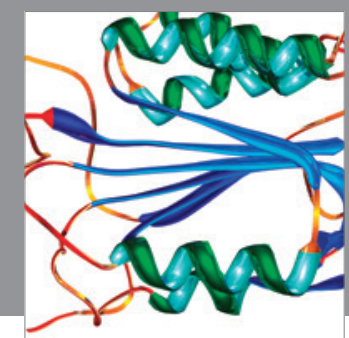

Disease Markers
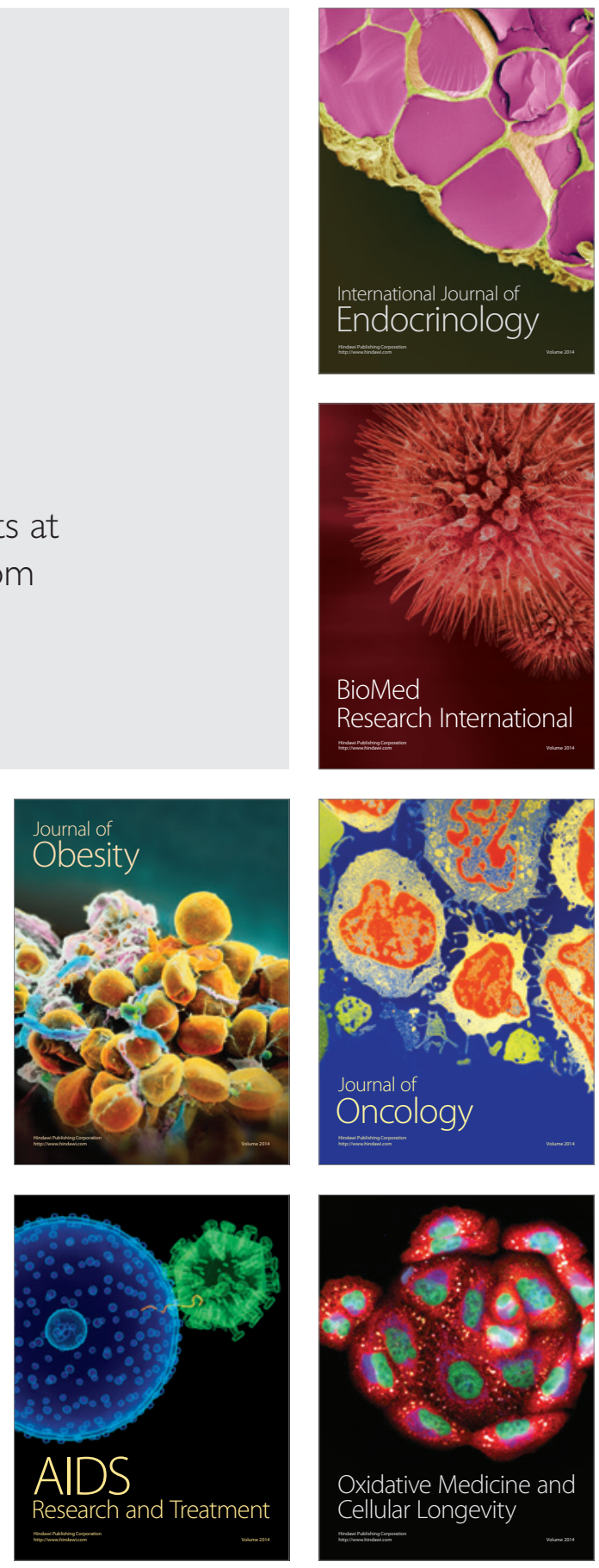